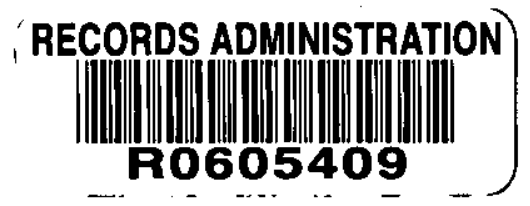

DPST-83-325

\title{
THE ANALYSIS OF DECONTAMINATED DEFENSE WASTE SALT SUPERNATE FOR I-129
}

\author{
WSRC Contact: \\ W. H. Carlton \\ Westinghouse Savannah River Company \\ Savannah River Site \\ Aiken, South Carolina 29808
}

A technical report being sent to OSTI and for distribution to the general public.

The information contained in this report was prepared in connection with work done under Contract No. DE-AC09-76SR00001 with the U.S. Department of Energy. By acceptance of this report, the publisher and/or recipient acknowledges the U.S. Government's right to retain a nonexclusive, royalty-free license in and to any copyright covering this report, along with the right to reproduce and to authorize others to reproduce all or part of the copyrighted report. 


\section{DISClaIMer}

This report was prepared as an account of work sponsored by an agency of the United States Government. Neither the United States Government nor any agency thereof, nor any of their employees, makes any warranty, express or implied, or assumes any legal liability or responsibility for the accuracy, completeness, or usefulness of any information, apparatus, product, or process disclosed, or represents that its use would not infringe privately owned rights. Reference herein to any specific commercial product, process, or service by the trade name, trademark, manufacturer, or otherwise, does not necessarily constitute or imply its endorsement, recommendation, or favoring by the United States Government or any agency thereof. The views and opinions of authors expressed herein do not necessarily state or reflect those of the United States Government or any agency thereof. 
DPST $-83-325$

TECHNICAL DIVISION

SAVANNAH RIVER LABORATORY

MEMORANDUM

TO: R. B. FERGUSON
CC: W. R. Stevens, III

E. I. Albenesius

W. V. Wright

J. R. Wiley

E. L. Wilhite

G. A. Carothers

C. J. Coleman

W. G. Winn

SRL Records (2)

ACe. NO. 97236

February 23, 1983

FROM: J. P. RYAN

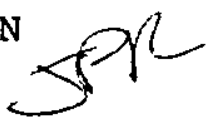

THE ANALYSIS OF DECONTAMINATED

DEFENSE WASTE SALT SUPERNATE FOR I-129

\section{SUMMARY}

A method is reported here for the analysis of I-129 in decontaminated defense waste salt solution at concentrations as low as 0.14 $\mathrm{pCi} / \mathrm{ml}$. Repeated analyses have been unable to confirm the presence of I-129 in decontaminated samples of Tank 24 supernate.

\section{INTRODUCTION}

The current flowsheet for the treatment of defense waste salt calls for the disposal of decontaminated salt solutions at an engineered burial site in the form of a mixture of soil, cement and salt. Although the major fission products will be removed in the decontamination process, radioiodine (I-129) has been identified as a potential environmental contaminant that could be released through the proposed disposal facility.

Present calculations, based largely on fission yield inventory estimates, indicate that I-129 will have no significant impact upon 
environmental quality in the salt disposal area. However, a reliable and sensitive analytical method is needed for I-129 in decontaminated salt supernate solutions, so that the environmental consequences of the disposal facility can be estimated with real rather than upper limit values. Current estimates of environmental impact use an upper limit estimate of $100 \mathrm{pCi} / \mathrm{ml}$ for the average concentration of I-129 in decontaminated waste salt. Preliminary data for Tank 24 reported herein, indicate that this estimate may be far too high.

\section{DISCUSSION}

The approach described here for the analysis of I-129 makes use of analytical technology that was developed at SRL for the NURE program. The method is a modified version of a procedure that was developed at ORNL for the specific purpose of measuring $I-129$ in fission waste.

The most important deviation with respect to the Oak $\mathrm{R}$ idge procedure has been to eliminate valence adjustment and solvent extraction steps that were intended to separate I-129 from other fission products in the waste sample. Instead, the major fission product separation occurs in the process decontamination step, using tetraphenylborate/sodium titanate precipitation and filtration. Iodine in the filtrate is then separated from sodium and any residual fission product activity by adsorbing it on anion exchange resin and rinsing with distilled water.

In order to validate the modified procedure it was necessary to prove that the adsorption of $I-129$ from the filtrate is quantitative. This was demonstrated, first with samples of simulated defense waste salt supernate, using I-l3l standards in overnight equilibrium distribution coefficient measurements, and then by column breakthrough experiments (see Appendix). Then, samples of decontaminated supernate from Tank 24 were analyzed. The technique of standard additions was applied to assure that I-129 recovery was both linear and quantitative. Working with I-129 standards, response linearity was established over at least three orders of magnitude in sample concentration, and over a factor of 25 in sample volume.

The new procedure is faster, simpler to employ, and is approximately. three times as sensitive as the solvent extraction procedure. The advantage in sensitivity is fairly important to the activation analysis, since the $\mathrm{C}_{f}-252$ activation facility at SRI has a relatively low neutron flux for this kind of analysis.

A secondary advantage of the new method is its avoidance of the carbon tetrachloride extraction solvent (a suspected carcinogen) that is used in the solvent extraction method. 

R. B. FERGUSON
DPST $-83-325$
February 23, 1983

Procedure for the Analysis of $1-129$ in

Decontaminated Defense Waste Salt Supernate

Reagents, Materials and Equipment

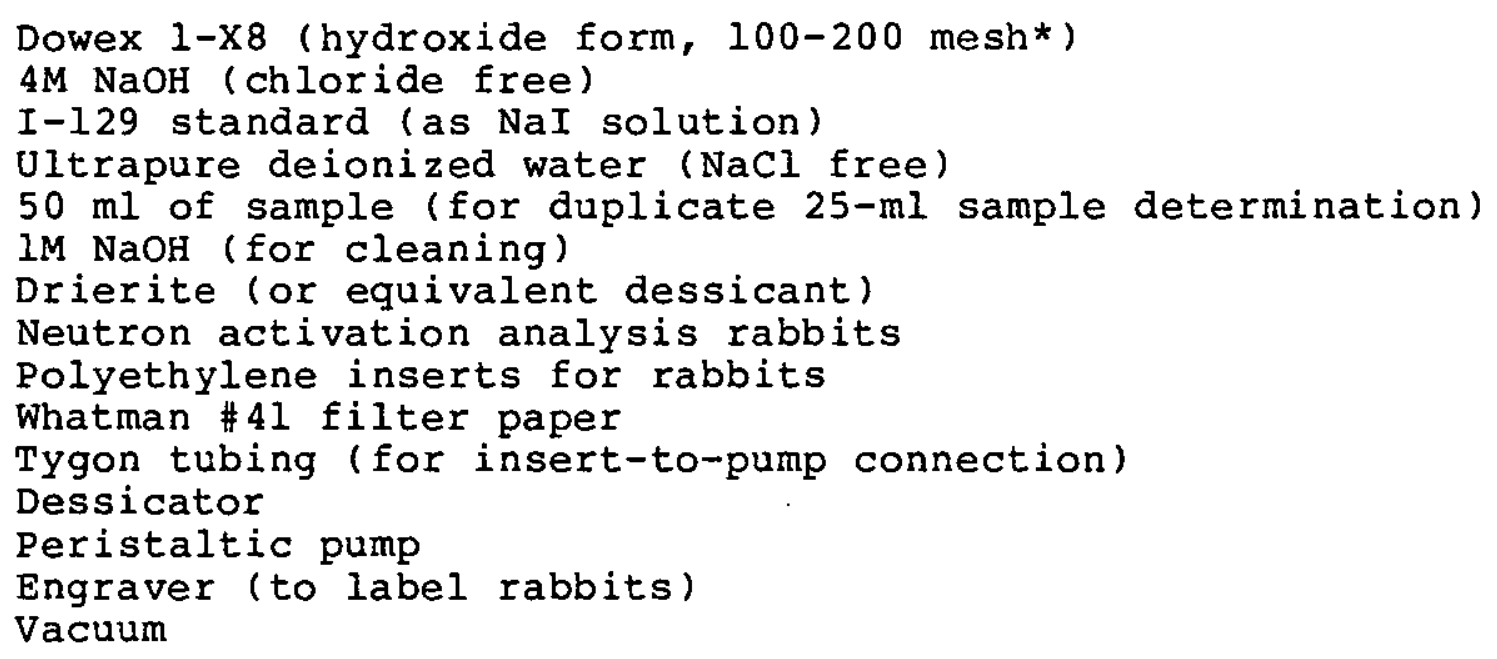

\section{Sample Preparation}

1. Check that the sample is decontaminated defense waste salt supernate. Sample should be caustic and should contain greater than $0.01 \mathrm{M} \mathrm{NO}_{2}^{-}$(to assure that I-129 is present as $\left.\mathrm{I}^{-}\right)$. Total non-volatile beta-gamma activity should not exceed $10^{5} \mathrm{~d} / \mathrm{m} . * *$

2. The columns are prepared as follows:

"Rabbit Columns" are made from polyethylene vials that fit exactly into the polyethylene "rabbits" used in pneumatically controlled sample changing for neutron activation analysis.

Preparation of "Rabbit" Columns

A. Drill a single $1 \mathrm{~mm}$ hole in the bottom of the vial.

* An equivalent resin AGl-X8 (Bio-Rad, Inc.), was also used with good results. The hydroxide conversion was made in our laboratory. Finer mesh resin (200-400 mesh) also works very well.

** For samples more radioactive than this, follow the decontamination procedure first. 
B. Cover the bottom (and hole with a piece of coarse filter paper (Whatman \#4I) cut to size.

C. Fill the column with a slurry of Dowex 1-X8 strong base anion exchange resin, or its equivalent (200-400 mesh, in the hydroxide form).

D. Connect the column to a peristaltic pump with plastic tubing (Tygon connections were used here). Set pump to $0.5 \mathrm{mi} / \mathrm{min}$, downflow.

3. Pass 5-10 $\mathrm{ml}$ of $4 \mathrm{M} \mathrm{NaOH}$ through the entire system. (Approximately $50 \mathrm{ml}$ of $\mathrm{NaOH}$ should be used if there is any chloride present on the resin.)

4. Pass $25.0 \mathrm{ml}$ of the salt supernate sample completely through the resin column.

5. Rinse column and tubing with $50 \mathrm{ml}$ of deionized (ultrapure) water.

6. Pump or draw air through the column for 5-10 minutes, being careful not to allow enough pressure to tear the filter paper.

7. Remove the column and place in a dessicator to dry under vacuum (with $\mathrm{CaCl}_{2}$ ). For RAF* analyses, the columns should be dried overnight. Samples going to the $C_{f}-252$ facility can be processed immediately.

8. Place the dry column in a "rabbit" for neutron activation. Place the columns upside down in the "rabbit." (This is especially important if the sample is to go to the RAF facility.)

9. "Rabbits" should be marked to indicate sample number and orientation prior to heat sealing (their lids).

Standardization

Analytical standards consist of aliquots of the salt supernate sample that have been spiked with a standardized I-129 solution (internal standard). At least three standards are normally required to demonstrate linear response and recovery by this technique of standard additions. However, once these are established, a single standard is sufficient to verify the 

R. B. FERGUSON
5
DPST-83-325
February 23,1983

recovery and response curves. Sample concentrations are then calculated by dividing the response by the slope of the calibration curve (counts/concentration).

With no analyte present in the sample, the standard curve is linear, and should pass through the origin if response is normalized by subtracting the appropriate blank (see Figure 1).

\section{Blanks}

The analytical blank consists of a "rabbit column" that has been treated exactly the same as the samples with the exception of sample introduction itself. The major interferences arise from the resin matrix and residual sodium, both of which can be accounted for by this blank.

Additional blank tests were made with simulated salt supernate solutions that contained trace amounts of Cs-137, chromium and other potential interferences. However, none of these appeared to be significant.

\section{Decontamination}

Discussion

The ion exchange concentration procedure is not designed for contaminated fission product waste. Samples of 15 year waste salt supernate which contain greater than $10^{5} \mathrm{~d} / \mathrm{m} / \mathrm{ml}$ of non-volatile beta-gamma activity should be decontaminated before being analyzed by this procedure.

Decontamination, specifically the removal of Cs-137, can be accomplished by the addition of an excess of sodium tetraphenylborate, or by passing the salt supernate sample through a cesiumspecific ion exchange bed consisting of 200-325 mesh Cs-100 resin (Duolite International). For analytical purposes a colimn of Cs-100 will decontaminate approximately 30 bed volumes of defense waste salt supernate.

For maximum accuracy, both decontamination methods require the employment of a yield monitor (I-131) to assure that I-129 is not being lost in the decontamination procedure. However, the loss of iodine in decontamination and concentration is so slight that good accuracy can be obtained without one. A decontamination procedure is described below. Iodine recovery was $97.7 \%$ for this procedure as monitored by an I-131 tracer. 
R. B. FERGUSON

\section{Decontamination Procedure}

Reagents:

I-131 Standard (approximately $10^{8} \mathrm{~d} / \mathrm{m} / \mathrm{ml} \mathrm{I}-131$, as $\mathrm{NaI}$ )

Sodium tetraphenylborate $(0.5 \mathrm{M})$

Sodium titanate/isopropanol ( $12 \mathrm{~g} / 1$ in slurry form)

Sample of defense waste salt supernate

1. Prepare a yield monitor standard ( $100 \mu l$ of $I-131$ standard made up to $63 \mathrm{ml}$ with $1 \mathrm{M} \mathrm{NaOH}$ ).

2. Obtain $60 \mathrm{ml}$ of supernate sample.*

3. Spike with $100 \mu 1$ of I-131 standard. Mix well.

4. Then add:
a. $400 \mu 1$ of sodium titanate slurry
b. $2.5 \mathrm{ml}$ of sodium tetraphenylborate solution.

5. Mix well and allow to settle.

6. Filter $50 \mathrm{ml}$ for analysis ( 1 sample +1 internal std).

7. Filter an additional $3 \mathrm{ml}$ for comparison with the yield monitor standard. Count each to determine iodine loss.

NEUTRON ACTIVATION PARAMETERS FOR I-129

$(\mathrm{Cf}-252$ facility)

Activation time: $3.33 \mathrm{hr}$.

Decay time: $13.0 \mathrm{hr}$.

Counting time: $5.6 \mathrm{hr}$.

Energy monitored: $0.536 \mathrm{MeV}$

Thermal neutron flux: $10^{9} \mathrm{~cm}^{-2} \mathrm{sec}^{-1}$

Geometry: Approximately $2 \mathrm{~cm}$ (automated and reproducible) Detection limit (on Dowex Resin normal sodium background). $=0.9 \pm 0.3 \mu \mathrm{g}$

\section{Reactor Activation Facility}

Activation time: $1.00 \mathrm{hr}$. Decay time: $28.0 \mathrm{hr}$.

Counting time: $5.6 \mathrm{hr}$ (at $773-\mathrm{A}$ ).

* This amount produces two $25 \mathrm{ml}$ samples for direct analysis. These amounts should be scaled up as needed if more than one internal standard is required. 

R. B. FERGUSON
DPST $-83-325$
February 23, 1983

Energy monitored: $0.536 \mathrm{MeV} .11 \mathrm{~cm}^{-2} \mathrm{sec}^{-1}$.
Thermal neutron flux: $8 \times 10^{-11}$.
Geometry: approximately $2 \mathrm{~cm}$ (at $773-\mathrm{A}$ ).
Detection limit: 0.022 ig
(on Dowex resin, normal sodium background).

\section{PRIMARY STANDARDS}

Three samples of a diluted I-129 standard were analyzed by beta scintiliation counting. The scintillation counts (corrected for background) were within 9.48 of the calculated activity of the 200 $\mu l$ standards. Counting error was less than 18 and sampling precision was +2.28 (RSD). Systematic error was high with respect to the calculated I-129 beta activity, indicating that standard and sample concentrations may be as much as 108 greater than reported. This error would not be significant, especially near the detection limit of the method, but subsequent standards will be analyzed to verify accuracy.

\section{$\underline{\text { RESULTS }}$}

Samples of decontaminated Tank 24 defense waste salt supernate were analyzed by the described procedure. No I-129 was detected (see Table III). The detection limit of the method was $3.9 \mathrm{pCi} / \mathrm{ml}$ ( $95 \%$ confidence) when the activation was performed at the $\mathrm{C}_{f}-252$

facility at SRL.

A sample was also activated at the RAF (Reactor Activation Facility). Again, no I-129 was detected. The detection limit was below $0.45 \mathrm{pCi} / \mathrm{ml}(70 \mathrm{ng} / 25 \mathrm{ml})$ for the sample and standard that were analyzed.

\section{CONCLUSIONS}

The new procedure appears to work well for the analysis of I-129 in decontaminated defense waste salt supernate samples. This should be borne out as more samples become available. The detection limits of this new procedure are more than adequate to identify hazardous levels of I-129 in defense waste supernate, if they exist. Even greater sensitivity would be obtainable by improving the resin washing technique for removing sodium, and by using a larger fraction of the resin capacity.

JPR : pmC

Att

\# 4 


\section{REFERENCES}

1. BATE, L. C. and STOKELY, J. R., "Determination of Iodine-129 In Mixed Fission Products by Neutron activation Analysis," USDOE Report ORNL/TM-7449, Oak Ridge National Laboratory, Oak Ridge, TN, October 1980.

2. LEE, L. M. and KILPATRICK, L. L., "Precipitation Process for Supernate Decontamination," USDOE Report DP-1636, Savannah River Laboratory, Aiken, SC. 
R. B. FERGUSON

9

DPST $-83-325$

February 23, 1983

\section{ACKNOWLEDGEMENTS}

Decontaminated defense waste salt supernate samples were provided by L. M. Lee and L. L. Kilpatrick.

Neutron activation analyses were performed by W. G. Winn and G. A. Carothers at the $\mathrm{C}_{\mathrm{f}}-252$ and Reactor Activation Facilities, respectively. 

R. B. FERGUSON
10
DPST $-83-325$
February 23, 1983

\section{APPENDIX}

\section{VALIDATION STUDY OF I-129 ANALYSIS BY DIRECT RESIN ADSORPTION AND NEUTRON ACTIVATION}

\section{Analysis of Resin by NAA}

Preliminary method validation involved analyzing the anion exchange resin (Dowex $1-\mathrm{X} 8$ ) to assure that its intrinsic background from the activation of chlorine, sodium and bromine would permit its use for activation analysis. The resin was first converted to the hydroxide form and rinsed with deionized water to remove sodium. Some samples were analyzed without further treatment. Others were treated with simulated decontaminated supernate (with TPB and Cs-137 and without) rinsed with pure deionized water, and analyzed. Also included was a series of I-129 standards in deionized water.

The results of these tests (Table I) showed that I-129 could be analyzed at the submicrogram level ( $1 \mu \mathrm{g}=1.61 \mathrm{x} 10^{-10} \mathrm{Ci}$ I-129) at SRL's $\mathrm{C}_{\mathrm{f}}-252$ facility.

Iodine Adsorption on Dowex 1-X8

Equilibrium Studies with I-131

Overnight batch equilibrium tests (Table II) demonstrated that I-129 should be adsorbed efficiently from caustic decontaminated supernate solutions containing large amounts of nitrate ( 2.4 molar) and nitrite ( 0.7 molar). The distribution coefficient (Kd) for iodide in these solutions was low enough to preclude the "resin slurry" approach from consideration as a quantitative method of I-129 concentration. However, a column concentration method appeared promising.

At constant $K d$, momentarily ignoring capacity considerations, the breakthrough volume $\left(V_{B}\right)$ for a column of this resin is, ideally,

$$
V_{B}=\rho K_{D} V_{B}
$$

where $\rho$ is the bulk density of the resin and $V_{B}$ is the volume of the column $\left(\mathrm{cm}^{3}\right)$.

For a $5 \mathrm{ml}$ "rabbit column" with a bulk density of roughly 0.75 $\mathrm{g} / \mathrm{cm}^{3}$, a $\mathrm{K}_{\mathrm{D}}$ of 29 indicates a breakthrough volume $(\mathrm{i} . \mathrm{e}$. $\mathrm{C} / \mathrm{Co}=$ $0.5)$ of 109 bed volumes. The maximum sample volume that can be treated (with $>958$ cumulative recovery) is a function of kinetics and must be measured by column breakthrough experiments. A rough estimate might be $70 \%$ of theoretical for an efficient column at reasonably low flow rates. 
R. B. FERGUSON $\quad 11$ DPST-83-325

Although it was performed with simulated defense waste salt supernate solutions, this experiment is strong evidence that the iodine in the supernate is in the form of an exchangable anion (I-) that can be efficiently concentrated with Dowex 1-x8. Additional evidence for this can be found in the column tests described below.

Column studies with I-131

(Simulated Defense Waste Salt Supernate)

Breakthrough studies were performed with I-131 in simulated defense waste salt supernate containing all of the major components of the decontaminated salt supernate that will be produced by the DWPF (Stage 2). This includes normal levels of iodine, chromium, and tetraphenylborate as well as nitrate, nitrite, hydroxide, and the other major components of the anticipated samples. The results of duplicate tests indicated no detectable breakthrough of I-13l under the sampling conditions described in the procedure $(25 \mathrm{ml}$ sample volume, $2 \mathrm{ml} / \mathrm{min}, 200-400$ mesh Dowex $1-x 8$ resin).

Column studies with $I-131$

(Tank 24 Defense Waste Salt Supernate)

The breakthrough curve for $\mathrm{I}-131$ on a 6-ml "rabbit column" of Dowex $1-X 8$ is shown in Figure 2. The feed was a sample of decontaminated supernate (from Tank 24) that had been spiked 24 hours earlier with I-13l. Trials were performed at two flow velocities. The results show that a volume flow rate of $2 \mathrm{ml} / \mathrm{minute}$ ( 20 column volumes/hr) could be processed through 100-200 mesh Dowex 1-X8 while still obtaining better than 978 recovery from a $30-\mathrm{ml}$ sample.

Before running this study, the spiked feed was allowed to equilibrate overnight to assure that the I-13l spike had sufficient time to exchange with any iodine already present (in the Tank 24 supernate sample). Since $I-131$ was recovered with approximately $100 \%$ efficiency, it is virtually certain that any $I-129 / I-127$ in the original filtrate sample would have been recovered as well.

\section{Valence Adjustment}

I-129 tracer tests were also used to prove that any I-129 in the salt. supernate samples was in a form ( ${ }^{-}$) that would be readily adsorbed by strong base anion exchange resin (Dowex 1). This was accomplished by verifying the conversion of iodate, a poorly adsorbed form, to iodide, in a recovery test. Actual samples of supernate and the concentration and analysis methods of this procedure were used.

A sample of $I-129$ was converted to the iodate form with a 10-fold excess of $\mathrm{NaOCl}$ (all in $1 \mathrm{M} \mathrm{NaOH}$ ). A $1.0 \mathrm{ml}$ aliquot of this I-13I 
$\begin{array}{lll} & \text { DPST }-83-325 \\ \text { R. B. FERGUSON } & 12 & \text { February } 23,1983\end{array}$

iodate stnadard was then made up to $25 \mathrm{ml}$ with Tank 24 salt supernate (decontaminated filtrate). This was allowed to equilibrate overnight before it was analyzed. A second standard, containing the same I-129 activity in the form of iodide, was made up the same way and analyzed directly. The entire $25-\mathrm{ml}$ volume of both samples was concentrated on "rabbit columns" and analyzed by NAA. An unspiked filtrate sample of Tank 24 decontaminated salt supernate was also analyzed to serve as the blank.

The results were in good agreement, with 938 of the I-129 iodate being recovered, compared to the I-129 iodide sample. Counting error was 4.98 (RSD). I-129 activity in the Tank 24 sample was less than $4 \mathrm{pCi} / \mathrm{ml}$.

JPR : pmc 
TABLE I

ANALYTICAL DETECTION LIMITS FOR I-129 AT THE SRL CE-252 FACILITY

Sample

Blank

(column and filter)

Resin Column Blank

TPB Supernate Blank

(10 $\mathrm{ml}$ simulated supernate)

Cs-137 Spiked Supernate Blank

(10 ml sample)

I-129 Standard

( $0.73 \mu \mathrm{g}$ in $10 \mathrm{ml}$ of distilled water)

I-129 Standard

(73.3 $\mu \mathrm{g}$ in $100 \mathrm{ml}$ of distilled water)

I-129 Standard

$(0.73 \mu \mathrm{g}$ in $100 \mathrm{ml}$ of distilled water)
$\frac{I-129 \text { Detected }}{(\mu \mathrm{g})}$

$<0.27(3 \sigma)$

$<0.41(3 \sigma)$

$<0.94(3 \sigma)$

$<0.99(3 \sigma)$

$0.69 \pm 0.20$

$73.3 \pm 1.5 *$

$0.99 \pm 0.26$

* All other samples normalized to this standard. 
R. B. FERGUSON

14

DPST $-83-325$

February 23, 1983

TABLE II

VERIFICATION OF IODINE (131) ADSORPTION ON DOWEX 1-X8

Aqueous

Solution

Deionized Water

IM $\mathrm{NaOH}$

Simulated Supernate

$\left(<10^{-8} \mathrm{M}\right.$ iodide)

Simulated Supernate

(including $1.6 \times 10^{-5} \mathrm{M} \mathrm{I}^{-}$ and saturated with tetraphenylborate)
Resin/Aqueous

(Mass Ratio)

$1: 10$

is

11

1
Kd I-131 Mass Distribution Ratio (Resin/Aqueous)

$$
1200
$$

900

32

29 
TABLE III

\section{TANK 24 DECONTAMINATED SALT SUPERNATE ANALYSIS} (Cf-252 Facility, SRL)

\begin{tabular}{|c|c|c|c|c|}
\hline Sample & $\begin{array}{l}I-129 \\
\text { added to } \\
\text { sample }(g)\end{array}$ & $\begin{array}{l}\text { Concentrated } \\
\text { Volume (m1) }\end{array}$ & $\begin{array}{l}\text { Response } \\
\text { ( Background } \\
\text { Normalized } \\
\end{array}$ & $\mathrm{pCi} / \mathrm{ml}$ \\
\hline$T k-24$ & $-\infty$ & 25 & $0 \pm 140$ & $<3.9$ \\
\hline $\begin{array}{l}\text { Tk-24 } \\
\text { STD A }\end{array}$ & $7.33 \times 10^{-6}$ & 25 & $3390 \pm 200$ & 47 \\
\hline $\mathrm{Tk}-24$ & --- & 1 & $-34 \pm 99$ & $<0$ \\
\hline $\begin{array}{l}\text { Tk-24 } \\
\text { STD } 3\end{array}$ & $7.33 \times 10^{-6}$ & 1 & $3874 \pm 130$ & $1.2 \times 10^{3}$ \\
\hline $\begin{array}{l}\text { TK-24 } \\
\text { STD C }\end{array}$ & $7.33 \times 10^{-5}$ & 1 & $42,500 \pm 400$ & $1.2 \times 10^{4}$ \\
\hline
\end{tabular}



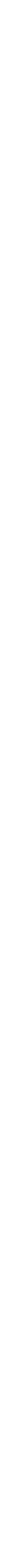


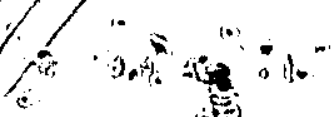

"?

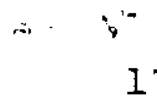

DPST-83-325

February 23, 1983

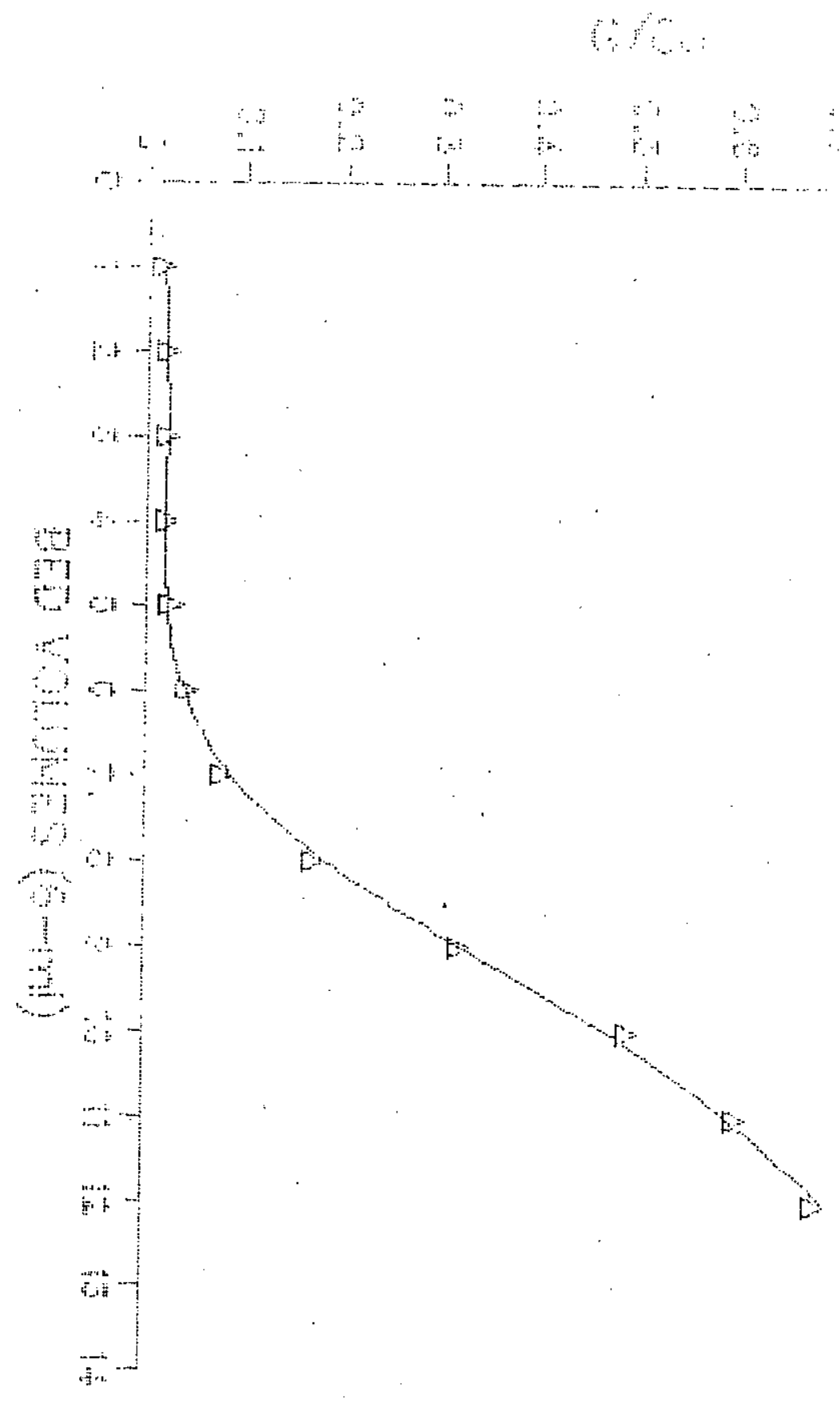

BEST AVALABLE COPY

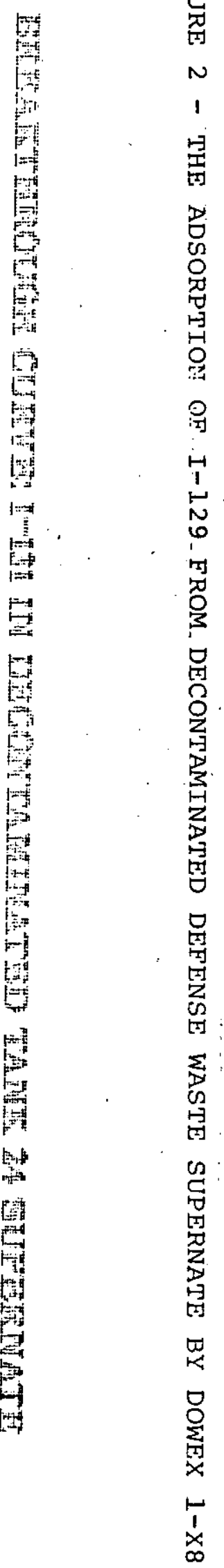

